\title{
Modelling National Medicine Inventory System Using System Dynamics
}

\author{
Patih Fathin Rizal ${ }^{1, *}$ Desy Anisya Farmaciawaty ${ }^{2,}$ Mursyid Hasan Basri ${ }^{3,}$ Nurul \\ Rachmania $^{4}$
}

\author{
${ }^{1}$ Institut Teknologi Bandung \\ ${ }^{2}$ Institut Teknologi Bandung \\ ${ }^{3}$ Institut Teknologi Bandung \\ ${ }^{4}$ Institut Teknologi Bandung \\ ${ }^{*}$ Corresponding author. Email: patih_rizal@sbm-itb.ac.id
}

\begin{abstract}
The availability of national medicines in Indonesia in the era of the national health insurance (JKN) has become a polemic that cannot be overcome instantly, such as medicine shortage and overstock. This situation will affect patient safety and continuity of health service by provider. Various stakeholders play an important role in fulfilling national medicines needs, namely Ministry of Health, pharmaceutical industry, health facilities, and Social Insurance Administration Organization (BPJS). This research aims to determine model for national medicines inventory system in Indonesia. Due to its complexity, system dynamics approach was used to develop the model. The model describes relationship among government regulation (medicine price, procurement process, national formulary), supplier performance, and health care provider behavior. In the near future, the proposed model will be used to evaluate the effectiveness of government regulation on national medicines inventory system.
\end{abstract}

Keywords: medicine inventory, government regulation, system dynamics.

\section{INTRODUCTION}

Government commitment to enhance Indonesia's human resource is shown from government spending in 2019. Government spending for health in 2019 is increasing 200\%, from Rp65.9 trillion in 2015 to Rp121.9 trillion in 2019 shown in figure 1.

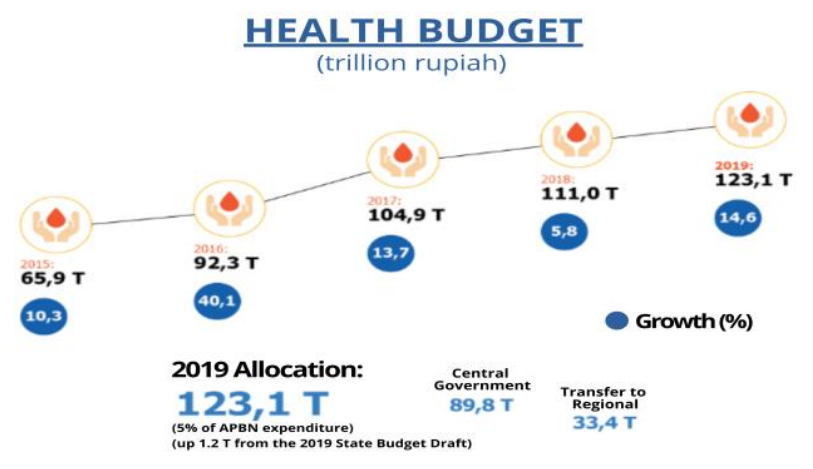

Figure 1. Health Budget 2019
Health budget have been allocated for National Health Insurance (JKN stands for Jaminan Kesehatan Nasional) program which now become Social Insurance Administration Organization (BPJS stands for (Badan Penyelenggaran Jaminan Sosial). Regarding the Law Number 24 of 2011 concerning BPJS, BPJS is working to perform health care insurance program. BPJS is held nationally based on the principle of social insurance and the principle of equity, with the aim of ensuring that participants receive the issue of maintaining health and protection in meeting basic health needs.

One of the basic needs of health is medicine. Various types, prices, and functions of medicines are available in the market. Under the National Social Security System (SJSN stands for Law 40/2004 and Law Health 36/2009, the government makes fornasnational formulary (fornas) which contains types of medicines based on medicine selection criteria as control of medicine use and e-catalogs based on results of results and negotiations between National Public Procurement Agency (LKPP stands for and the 
pharmaceutical industry as a cost control medicine shown in figure 2 health care provider.

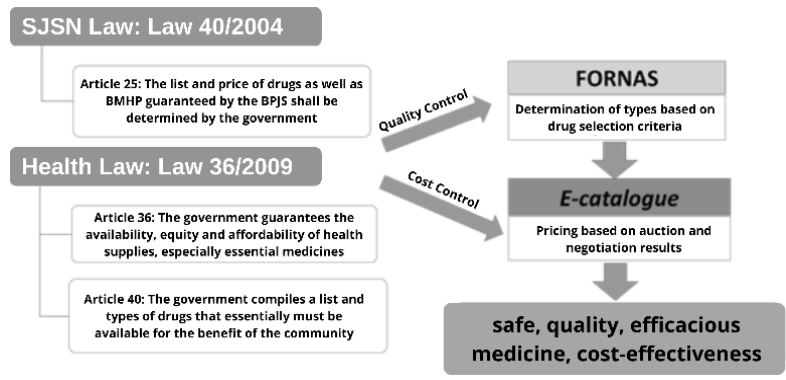

Figure 2. Medicine regulation [2]

\subsection{Business Issue}

Medicine procurement scheme in figure 3 starts from the determination list of medicines needed by the Fornas. From National Ministry of Health, National Ministry of Health has compiled a drug needs planning (RKO stands for Rencana Kebutuhan Obat) which lists the amount of medicine needed in health facilities for 1 year. Followed by preparation of medicine prices with Owner Estimate (HPS stands for Harga Perhitungan Sendiri) by the Medicine Price Team. The work of the Medicine Price Team then proceeded to LKPP for the procurement process with medicine e-catalogs and then LKPP conducted auctions and negotiations. The auction process at LKPP was then announced as the winner in the e-catalogue list. The health care providers in all regions, including clinics, health centers, hospitals make purchases through e- procurement to pharmaceutical companies.

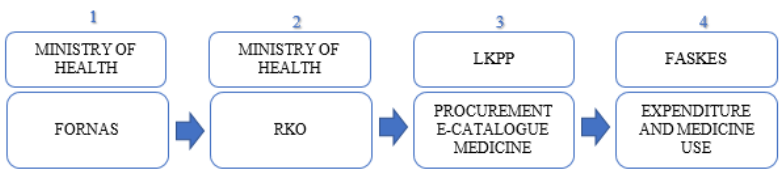

Figure 3. Medicine procurement scheme

\subsubsection{Fornas}

Fornas (national formulary) is a list of selected medicines needed and must be available in health facilities in the context of implementing JKN. Meanwhile e-catalogue is used to be price control for medicine. But in fact, some medicines are not listed in Fornas but appear in e-catalogue and vice versa. As a result, some Fornas medicines health facilities iwere in limited supply and difficult to provide and some were not even available at healthcare facilities. This condition results in a medicine that does not have a price reference as the basis for BPJS Health to pay claims. Furthermore, lack of harmonization between the e-catalogue and the Fornas implied that healthcare facilities did not always use the e-catalogue to procure.

\subsection{2. $R K O$}

In the beginning of the year, health facilities must forecast their medicine needs for the following years. Forecast must be calculated based on their historical data and their inventory on hand. However, health facilities which uploaded their RKO didn't use forecast as it should be. Some of health facilities are using their past medicine need as their future medicine needs, some other are buy as many as possible as long they have money. These actions lead into uncertainty national medicine stock. On the other hand, government states that all RKO must be multiplied by 1.5 to ensure national medicine stock or to make safety stock for national medicine. However, this is still not enough to cover all medicine needs, since not all health facilities upload their RKO.

RKO data compiled by the Ministry of Health from the Health Office and health facilities is not yet accurate because not all DHOs and health facilities have submitted RKO to the Ministry of Health as the basis for procurement of medicines in e-catalogue, health facilitiesRKO in Government's faskes was $52 \%$, Private $2 \%$, and Pharmacy PRB 15\%. Realization of medicine spending on e-catalogs in 2016 according to the KPK went far beyond the RKO data which only reached 30$40 \%$ [2]. Even though this RKO is the reference of the Ministry of Health in determining the type of medicine and the number of medicines to be auctioned. Whereas in 2017 government and private health facilities that have not reported RKO were as many as 1387 or $46.23 \%$ of the total work units. During 2018, government and private health facilities that have not reported RKO were as many as 884 or $28.31 \%$ of the total work units.

\subsubsection{Procurement e-catalogue medicine}

In 2016, there were still delays and failures of the medicine auction by LKPP which resulted in the new ecatalogue being accessible in April. Then, the implementation of sanctions on medicine providers that default also has not been carried out by LKPP even though the sanctions have been regulated in LKPP. This condition resulted in the percentage of medicine expenditure in e-catalog being less than $70 \%$.

According to the Director of LKPP Catalogue System Development, Emin Adhi Muhaemin, the issue of medicine scarcity in BPJS health facilities occurred because there was a tendency for most hospitals to process RKO for medicines in the second and third quarters.

Besides, RKO data has not related to e-catalogue, so health facilities that did not report RKO were still able to buy medicine in e-catalogue because there were no written sanctions and firm for health facilities who did not report the RKO. This has the potential to cause a void of certain medicines due to overload in ordering and result in the pharmaceutical industry experiencing over capacity in its production. The other way around, 
there could be an excess stock of certain medicines that were previously included in the RKO, but then were not purchased according to the plan to result in losses for the pharmaceutical industry which had already produced large quantities of auctioned medicines. Some cases shown that health facilities didn't upload their RKO since they have high inventory in hand.

\subsubsection{Expenditure and medicine use}

Based on President Decree number 19-year 2016, BPJS must pay health facilities billing from 3 up to 15 days after health facilities claim to BPJS. In most of cases, health facilities already claim to BPJS, but it took several months to receive payment from BPJS. On the other hand, BPJS said that it was health facilities problems that they cannot fulfill documents required to claim from BPJS. The uncertainty payment from BPJS makes health facilities cannot pay medicine to industry or distributor. This will lead into disobedient of health facilities that makes industry blacklist that health facilities from buying medicine until that health facilities pay their debt.

Problems regarding the practical use of the ecatalogue and the Fornas have been reported. For instance, it was found that many health facilities rarely use the e-catalogue to procure medicines. Moreover, of all medicines prescribed in 2015 , up to $40 \%$ were not listed in the Fornas. This may explain the increase of out of pocket payment in 2015 to $50 \%$. Out of these, $70 \%$ were found to be out of pocket payment for medicines, which obviously contrasts the philosophy of UHC.

The director of the hospital and the hospital's medical committee should approve when health facilities prescribe medicines not listed in the Fornas. Notably, the approved medicine is not reimbursed by BPJS-Health out of pocket payment which implies either out of pocket payment or payment from the hospital is needed.

\section{METHODS}

System is defined as a collection of elements that continually interact over time to form a unified whole. Dynamics refers to change over time or constantly changing. System dynamics is a method to enhance learning in complex systems [3]. It concerns about nonlinear dynamics and feedback control that change over time. System dynamics can analyze problems using an entire system to estimate the dynamics of developing trends in individual systems [4].

$\mathrm{SD}$ is a computer simulation method for understanding systems and how they change in terms of feedback mechanisms or loops [5]. There are 6 steps to simulate using system dynamics:

- Define problems and boundaries of the issue.
- Develop casual loop diagrams for representing feedback process

- Make stocks and flows diagram based on casual loop diagrams.

- $\quad$ Put formulation, parameters, and conditions into stocks and flows diagram.

- $\quad$ Check the model with reality.

- $\quad$ Simulate and analyze the result.

\subsection{Model Description}

National medicine stock is a stock of medicines available in e-catalogue produced by pharmaceutical industry. National medicine stock is influenced by the number of medicine requests from health facilities. There are 2 types of health facilities, registered health facilities which get IDs in e-monev and health facilities that are not registered which do not get IDs in e-monev. Health facilities that are not registered can be caused by several reasons, such as not registering online or already register themselves but still not getting the ID to enter emonev.

Registered health facilities forecast medicine usage for the next year through e-monev. Then the amount of forecast medicine usage will be multiplied by government production policy and become RKO. The method on doing forecast is different from each health facilities. Some health facilities use their previous demand as their next year forecasting, the other health facilities forecast by calculating demand and current inventory level. Purpose of government production policy is to provide safety stock in the national medicine stock. Furthermore, RKO will become the basis for determining the amount of medicine production from the pharmaceutical industries.

Unregistered health facilities also forecast their medicine usage. They o nowill not upload their medicine usage, but they still buy medicine from e-catalogue.

In the following year, registered health facilities and unregistered health facilities will purchase medicines through e-catalogue. Health facilities will be directly connected with the pharmaceutical industry from the medicines they will buy on e-catalogue. The number of medicines available in the pharmaceutical industry will adjust to the amount of RKO. Medicine buyers are not only from registered health facilities but also from unregistered health facilities.

\subsection{Causal loop diagram}

Causal loop diagram is used to represent the feedback of the process. Causal loop diagram consists of variable connected by arrow to show influences among variables. Each causal link is assigned with positive $(+)$ or negative (-) that indicates dependency of variable when independent variable changes. 
Causal loop diagram can be developed based on factors included in model description of national medicine stock. Specific factors affect national medicine stock such as government production policy and the amount of RKO. Figure 4 shows interactions among those key factors.

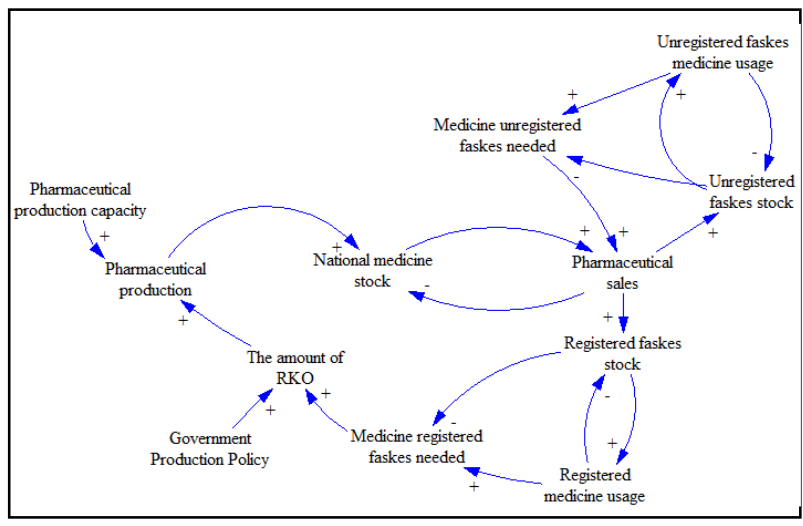

Figure 4. Causal Loop Diagram

\section{RESULTS AND DISCUSSION}

Based on causal loop diagram, it can be seen the relationship between variables, which is national medicine stock, industry sales, unregistered health facilities stock, unregistered medicine usage, medicine unregistered needed, registered health facilities stock, medicine usage, medicine needed, the amount of RKO, government production policy, pharmaceutical production capacity, and pharmaceutical production.

National medicine stock is affected by several variables. As national medicine stock increase, pharmaceutical sales also increase because pharmaceutical can sale more when there is more stock available. When pharmaceutical can sale more, national medicine stock will decrease. The number of pharmaceutical sales is determined by medicine registered and unregistered health facilities needed. The higher medicine registered and unregistered health facilities needed, the higher the pharmaceutical sales.

Each registered and unregistered health facilities needs is affected by their medicine usage and stock. When registered and unregistered health facilities use more medicine, their stock will be decreasing and increase their needs for medicine. In the other way, when stock is increasing, registered and unregistered health facilities can use more medicine and their needs for medicine for next period is decreasing.

The amount of RKO is only affected by medicine registered health facilities needed and government production policy. If medicine in registered health facilities needed is increasing, the amount of RKO will also increase, and if government production policy is increasing, the amount of RKO will also increase.
Pharmaceutical will increase its production when pharmaceutical production capacity is increasing and when the amount of RKO is increasing as well. National medicine stock will be increased when pharmaceutical production is increasing.

\section{CONCLUSION}

There are several variables in which relationship can be seen in causal loop diagram. Based on causal loop diagram, there are several schemes might be occurred:

- Shortage in the national medicine stock because the number of medicine buyers, registered and unregistered faskes, is more than the number of registered faskes sending RKO.

- Number of medicines available is greater than medicine purchased, caused by high government production policy or some registered faskes didn't buy medicines even though they have sent their RKO.

- Unknown forecasting method might lead to inaccurate medicine needed, the amount of RKO, pharmaceutical production, and national medicine stock.

- If pharmaceutical production capacity is lower than it should be, production will be lower, and national medicine stock will also be lower.

To be able to make further decision on maintaining national medicine stock at optimum level, the existing causal loop diagram should be developed into stockflow diagram. Mathematics equation will be needed to view the result from stock-flow diagram

\section{REFERENCES}

[1] Kemenkeu, "Kemenkeu," 2019. [Online]. Available: http://visual.kemenkeu.go.id/anggarankesehatan-apbn-2019/.

[2] N. Ariati, "Tata kelola obat di era sistem Jaminan Kesehatan Nasional (JKN)," Direktorat Penelitian dan Pengembangan KPK, Jakarta, 2017.

[3] J. D. Sterman, Business Dynamics: System Thinking and Modelling for a Complex World. Boston: McGraw-Hill, 2004.

[4] C. Chen, L.-g. Shao, L. Xu and J.-c. Shang, "A case study predicting environmental impacts of urban transport planning in China," Springer Science \& Business Media B. V., pp. 169-177, 2008.

[5] J. Chu, J. Chen and J. Zou, "Future scale and market capacity of urban water environmental infrastructure in China: a system dynamic model," Elsevier, pp. 1-7, 2002. 